\title{
A Snare Retrieval Experience of Coil Migration in a Large Coronary Artery Fistula
}

\author{
Mithat Selvi, Hasan Gungor', Sevil Gulasti ${ }^{1}$ \\ Department of Cardiology, Cine State Hospital, 'Department of Cardiology, Adnan Menderes University, Aydin, Turkey
}

\section{Abstract}

A 45-year-old female patient was referred due to the abnormal myocardial perfusion scintigraphy showing ischemia in the inferior and lateral wall. Coronary arteries were normal, and a large fistula was detected from the proximal portion of the circumflex coronary artery $(\mathrm{Cx})$ draining into the pulmonary artery. Percutaneous closure of the coronary artery fistula (CAF) was considered, and a $3 \mathrm{~mm} \times 50 \mathrm{~mm}$-Balt coil was planned to place the proximal portion of the fistulized artery. Unfortunately, during placement of the coil, it was opened early and migrated to the proximal segment of the $\mathrm{Cx}$, the left anterior descending artery, and the distal part of the left main coronary artery. A snare was moved into the extra backup guiding catheter immediately. The migrated coil was retrieved with the snare successfully. Subsequently, $4 \mathrm{~mm} \times 12 \mathrm{~mm}$ and $2 \mathrm{~mm} \times 25 \mathrm{~mm}$-Balt coils were placed in the mid portion of the fistulized artery until total occlusion was obtained. A CAF is described as a direct connection between one or more of the coronary arteries and a cardiac chamber or great vessel. The fistula may cause serious hemodynamic disturbances such as myocardial ischemia, high-flow heart failure, right ventricle volume overload, endocarditis, rupture, thrombosis, embolism, and arrhythmias. Percutaneous closure is the prior technique, in the absence of complex conditions such as multiple fistulas and large fistula branches and in cases where the fistula can be simply reached. There have been very rare data which contain complications about the percutaneous closure of CAFs.

Keywords: Coil migration, coronary artery fistula, snare

\section{INTRODUCTION}

A coronary artery fistula (CAF) is described as a direct connection between one or more of the coronary arteries and a cardiac chamber or great vessel. This is a rare abnormality and its definite incidence is unclear. ${ }^{[1]}$ Although majority of cases are asymptomatic, the fistula may cause serious hemodynamic disturbances such as myocardial ischemia, high-flow heart failure, right ventricle volume overload, endocarditis, rupture, thrombosis, embolism, and arrhythmias. ${ }^{[2]}$ The closure is required for symptomatic patients and fistulas with high-flow rate. Percutaneous closure is the prior technique, in the absence of complex conditions such as multiple fistulas and large fistula branches and in cases where the fistula can be simply reached. ${ }^{[2,3]}$ We present a rare complication of coil embolization where the coils migrated native circumflex artery. Subsequently, the coils are drawled back by a snare successfully.

\section{Case Report}

A 45-year-old female patient was referred to coronary angiography due to the abnormal myocardial perfusion

\begin{tabular}{|l|l|}
\hline \multicolumn{2}{|c|}{ Access this article online } \\
\hline Quick Response Code: & Website: \\
& http:/www.ijcva.com \\
\cline { 2 - 2 } & \\
& \\
\hline
\end{tabular}

scintigraphy showing ischemia in the inferior and lateral wall. Her cardiovascular examination was normal. There were no significant findings except poor R-wave progression on the electrocardiogram. Echocardiography revealed that the left ventricular ejection fraction was $65 \%$ and the left ventricular diastolic dysfunction was Grade 1 . There were no serious valve diseases additively. Coronary angiography was performed to investigate ischemic origin. Coronary arteries were normal, but a large fistula was detected from the proximal portion of the circumflex coronary artery $(\mathrm{Cx})$ draining into the pulmonary artery [Figure 1]. We assessed the patient's status as a coronary steal phenomenon due to the arteriovenous shunt caused by a large fistula. Percutaneous closure of the CAF was considered and a $3 \mathrm{~mm} \times 50 \mathrm{~mm}$-Balt coil was planned to place the proximal portion of the fistulized artery. Unfortunately, during placement of the coil, it was opened early and migrated to the

Address for correspondence: Dr. Mithat Selvi, Department of Cardiology, Cine State Hospital, 09500 Aydin, Turkey. E-mail: drmithatselvi@gmail.com

This is an open access journal, and articles are distributed under the terms of the Creative Commons Attribution-NonCommercial-ShareAlike 4.0 License, which allows others to remix, tweak, and build upon the work non-commercially, as long as appropriate credit is given and the new creations are licensed under the identical terms.

For reprints contact: reprints@medknow.com

How to cite this article: Selvi M, Gungor H, Gulasti S. A snare retrieval experience of coil migration in a large coronary artery fistula. Int $\mathrm{J}$ Cardiovasc Acad 2018;4:37-9. 
proximal segment of the $\mathrm{Cx}$, the left anterior descending artery, and the distal part of the left main coronary artery [Figure 2a]. A snare was moved into the extra backup guiding catheter immediately. The migrated coil was retrieved with the snare successfully [Figure 2b]. Subsequently, $4 \mathrm{~mm} \times 12 \mathrm{~mm}$ and $2 \mathrm{~mm} \times 25 \mathrm{~mm}$-Balt coils were placed in the mid portion of the fistulized artery until total occlusion was obtained [Figure 2c].

\section{DISCUSSION}

A CAF is described as a direct connection between one or more of the coronary arteries and a cardiac chamber or great vessel. Its most commonly congenital and its definite incidence are unknown. However, an acquired fistula can be occur subsequent to chest traumas or as a complication of percutaneous coronary interventions and coronary artery bypass graft surgery. ${ }^{[4]}$ Pathological mechanisms of CAFs include variety of theories. The presence of an accessory coronary artery from pulmonary artery is one of these theories. On the other hand, embryological hypothesis has been generated such as persistence of intertrabecular spaces and fetal sinusoids, that normally obliterate to form the adult coronary capillary network ${ }^{[4]}$ The right coronary artery is the most common origin of the CAFs with a frequency of $50 \%-60 \%$. The prevalence of drainage sites of CAFs are as follows: right atrium (19\%-26\%), pulmonary artery $(15 \%-20.2 \%)$, right ventricle $(14 \%-40 \%)$, coronary sinus $(7 \%)$, left atrium $(5 \%-6 \%)$, left ventricle $(2 \%-19 \%)$, and superior vena cava (1\%). ${ }^{[2]}$ In our case, a large fistula was detected from the proximal portion of $\mathrm{Cx}$ artery draining into the pulmonary artery.

Most CAFs are thought to be incidentally detected on routine examination or during coronary angiography. The left-to-right shunt or the presence of coronary steal phenomenon generally determines the severity of symptoms. Exertional dyspnea is the most common symptom with a frequency of $60 \%$ for the patients with CAFs. Endocarditis in the fistula (20\%), congestive heart failure (19\%), angina pectoris $(3 \%-7 \%)$,

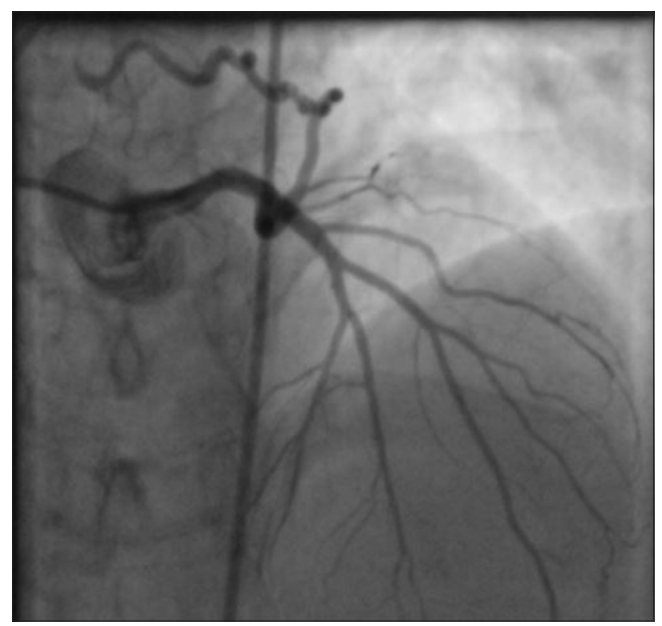

Figure 1: A large fistula which was draining into the pulmonary artery from the proximal portion of circumflex coronary artery syncope, palpitations, myocardial infarction, cardiac arrhythmias, pulmonary hypertension, hemopericardium, and sudden cardiac death are the other clinical situations which have been seen in the patients with CAFs. ${ }^{[2]}$

Multidetector computed tomography and magnetic resonance imaging are noninvasive tools to confirm the CAF entry site and patency of shunt. Radionuclide studies can be opted to detect ischemic regions of the myocardium. If the patient has restricted myocardial ischemia territory $(<10 \%$ left ventricular surface area) and is asymptomatic pharmacotherapy is the first-line treatment. ${ }^{[5]}$ According to the American College of Cardiology/American Heart Association guidelines, "percutaneous or surgical closure is a Class I recommendation for large fistulae regardless of symptoms and for small-to-moderate size fistulae with evidence of myocardial ischemia, arrhythmia, ventricular dysfunction, ventricular enlargement, or endarteritis." ${ }^{[6]}$ In our patient, the nuclear test has confirmed her symptoms with wide myocardial ischemia territory. Hence, we decided to closure of her fistula that cause of the coronary steal phenomenon.

Percutaneous closure is the prior technique, in the absence of complex conditions such as multiple fistulas and large fistula branches and in cases where the fistula can be simply reached. ${ }^{[2,3]}$ In addition, excessive vessel tortuosity and lumen diameter are determinative parameters for surgical closure. Steel coils, umbrella devices, and covered stents are utilized for percutaneous closure of the CAFs. The selection of device and technique depend on the anatomical properties of the fistula which contain age and size of the patient, size of the occluded vessel, and catheter support for tortuosity. ${ }^{[2,4]}$ We consider the patient's fistula characteristics and choose coil embolization through femoral approach.

In the literature, there have been very rare data which contain complications about percutaneous closure of CAFs. Armsby et al., have reviewed the results of percutaneous closure in 45 patients. ${ }^{[7]}$ Unretrieved device embolization to tricuspid valve or distal pulmonary artery were seen about

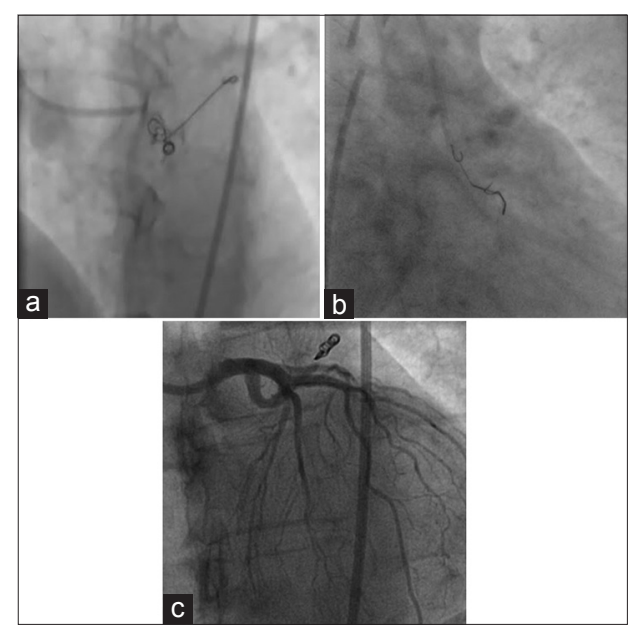

Figure 2: (a-c) The migrated coil (a). Retrieving of the migrated coil with the snare (b) Embolization of the fistulized artery with Balt coils successfully (c) 
four patients in their study. Furthermore, there was only one procedure-related death $(2.2 \%)$ due to embolization of a coil, the left $\mathrm{Cx}$ artery that led to the left $\mathrm{Cx}$ artery dissection.

\section{Conclusion}

Even if the coils do migrate, they can be retrieved with snares. This case shows the unexpected complication of percutaneous closure of CAFs and successful management of this complication using a snare.

\section{Declaration of patient consent}

The authors certify that they have obtained all appropriate patient consent forms. In the form the patient(s) has/have given his/her/ their consent for his/her/their images and other clinical information to be reported in the journal. The patients understand that their names and initials will not be published and due efforts will be made to conceal their identity, but anonymity cannot be guaranteed.

\section{Financial support and sponsorship}

Nil.

\section{Conflicts of interest}

There are no conflicts of interest.

\section{REFERENCES}

1. Qureshi SA. Coronary arterial fistulas. Orphanet J Rare Dis 2006;1:51.

2. Challoumas D, Pericleous A, Dimitrakaki IA, Danelatos C, Dimitrakakis G. Coronary arteriovenous fistulae: A review. Int J Angiol 2014;23:1-10.

3. Gowda RM, Vasavada BC, Khan IA. Coronary artery fistulas: Clinical and therapeutic considerations. Int J Cardiol 2006;107:7-10.

4. Said SA, Nijhuis RL, Akker JW, Takechi M, Slart RH, Bos JS, et al. Unilateral and multilateral congenital coronary-pulmonary fistulas in adults: Clinical presentation, diagnostic modalities, and management with a brief review of the literature. Clin Cardiol 2014;37:536-45.

5. Sibille L, Boudousq V, Soullier C, Rossi M, Mariano-Goulart D. Tc-99m tetrofosmin SPECT in coronary cameral fistula. Clin Nucl Med 2009;34:473-4.

6. Warnes CA, Williams RG, Bashore TM, Child JS, Connolly HM, Dearani JA, et al. ACC/AHA 2008 Guidelines for the Management of Adults with Congenital Heart Disease: Executive summary: A report of the American College of Cardiology/American Heart Association Task Force on Practice Guidelines (writing committee to develop guidelines for the management of adults with congenital heart disease). Circulation 2008;118:2395-451.

7. Armsby LR, Keane JF, Sherwood MC, Forbess JM, Perry SB, Lock JE, et al. Management of coronary artery fistulae. Patient selection and results of transcatheter closure. J Am Coll Cardiol 2002;39:1026-32. 